\title{
PARTO DA VIOLÊNCIA: OS LIMITES ENTRE A CONDUTA MÉDICA NECESSÁRIA E A VIOLÊNCIA OBSTÉTRICA
}

\section{FERNANDA MOREIRA HUDSON NASCIMENTO}

Graduanda em Direito, modalidade integral, pela Escola Superior Dom Helder Câmara de Belo Horizonte - MG. E-mail: fernanda.hudson@outlook.com.

\section{CAIO AUGUSTO SOUZA LARA}

Mestre e Doutor em Direito pela Faculdade de Direito da Universidade Federal de Minas Gerais - UFMG. Professor da Escola Superior Dom Helder Câmara. Pesquisador associado ao Programa RECAJ-UFMG - Acesso à Justiça e Solução de Conflitos. Secretário de Comunicação do Conselho Nacional de Pesquisa e Pósgraduação em Direito - CONPEDI. Belo Horizonte-MG. E-mail: caiolarabh@yahoo.com.br.

\section{RESUMO}

O tema-problema da pesquisa que se desenvolve é a violência obstétrica sofrida pelas mulheres no Brasil, muitas vezes camuflada pela liberdade médica para fazer o possível para salvar uma vida. Segundo o portal "As faces da violência obstétrica", da Universidade Federal do Rio Grande do Sul, "o termo violência obstétrica se refere aos diversos tipos de agressão a mulheres gestantes, seja no pré-natal, no parto ou pós-parto, e no atendimento de casos de abortamento". As agressões podem ser físicas, verbais, ou até mesmo a simples recusa ao atendimento. Segundo o estudo "Mulheres brasileiras e gênero nos espaços público e privado", feito pela Fundação Perseu Abramo em parceria com o SESC, em 2010, 1 em cada 4 mulheres no Brasil sofreram alguma forma de violência obstétrica. Mas, talvez, os dados possam ser ainda mais desconfortantes. Os casos de violência 
Personalidade Acadêmica Homenageada:

Raymundo Juliano Feitosa (Universidade Federal do Rio Grande do Norte - UFRN)

obstétrica são mais comuns do que parecem. De acordo com dados divulgados em 2015 pela revista Época, 75\% das mulheres em todo o Brasil não receberam alimentação durante o trabalho de parto; $73 \%$ não tiveram acesso a procedimentos não medicamentosos para o alívio da dor, como banho quente; $71 \%$ não tiveram direito a acompanhante, o que é previsto por lei desde 2005; e 25\% afirmam ter sido desrespeitadas na gestação ou parto. É preciso estabelecer uma diferença entre a conduta médica necessária para salvar a vida de seus pacientes e a violência obstétrica. Um profissional não pode se isentar da responsabilidade de seus atos violentos desnecessários, uma vítima não pode ser banalizada. Não podemos fechar os olhos para os atos violentos que ocorrem, sim, no meio médico, não podemos ignorar que a violência obstétrica existe. O problema objeto da investigação científica proposta é: qual o limite entre a conduta médica necessária e a violência obstétrica? A partir das reflexões preliminares sobre o tema, é possível afirmar inicialmente que a conduta médica passa a se caracterizar como violência quando não era essencial para garantir a sobrevivência dos pacientes, ou, mesmo que necessária, poderia ser feita de outra forma não violenta. Deve-se questionar também se havia circunstâncias que impedissem a informação ao paciente dos procedimentos tomados e da forma que foram tomados e se, havendo a possibilidade de informação, o procedimento foi consensual. $O$ objetivo geral do trabalho é analisar a conduta médica diante de mulheres em condição de vulnerabilidade e constatar quais atos são caracterizados como violência obstétrica. $O$ trabalho também busca enfatizar a relação existente entre a violência sofrida por mulheres antes, durante e após o parto e o pensamento intrínseco na sociedade brasileira de superioridade do gênero masculino e objetificação da mulher. A pesquisa que se propõe pertence à vertente metodológica jurídico-sociológica. No tocante ao tipo de investigação, foi escolhido, na classificação de Witker (1985) e Gustin (2010), o tipo jurídico-projetivo. O raciocínio desenvolvido na pesquisa será predominantemente dialético. De acordo com a técnica de análise de conteúdo, afirma-se que se trata de uma pesquisa teórica, o que será possível a partir da análise de conteúdo dos textos doutrinários, normas e demais dados colhidos na pesquisa. Como conclusão do trabalho, tem-se que a cultura machista intrínseca na 
Personalidade Acadêmica Homenageada:

Raymundo Juliano Feitosa (Universidade Federal do Rio Grande do Norte - UFRN)

sociedade brasileira impõe certa superioridade do homem em relação à mulher, que resulta no pensamento de poder e controle, responsável pelo comportamento autoritário e desrespeitoso no meio obstétrico. Embora existam normas de proteção à parturiente, a verdade é que a situação vulnerável das mulheres em trabalho de parto as deixa suscetíveis a graves violações de seus direitos fundamentais.

PALAVRAS-CHAVE: Direito da mulher; Violência Obstétrica; Saúde; Agressão.

\section{REFERÊNCIAS}

ARAÚJO, Ligia Gondim; FROTA, Maria Helena de Paula. Monitoramento eletrônico como medida de proteção às mulheres vítimas de violência. Revista Conhecer: debate entre o público e o privado. Vol. 08, № 20. Fortaleza, 2018. Disponível em: https://revistas.uece.br/index.php/revistaconhecer/article/view/1053/963. Acesso em 18 maio 2019.

AS FACES da violência obstétrica. Portal UFRGS. 05 jan 2018. Disponível em: https://www.ufrgs.br/jordi/172-violenciaobstetrica/violencia-obstetrica/. Acesso em: 01 maio 2019.

BENSON, Heidi. Move Over, Joan Didion / Make room for Rebecca Solnit, California's newest cultural historian. Portal SF Gate. 13 jun 2004. Disponível em: https://www.sfgate.com/magazine/article/Move-Over-Joan-Didion-Make-room-forRebecca-2713901.php. Acesso em: 30 abr 2019.

BRASIL. Código de Ética Médica de 2009. Disponível em: https://portal.cfm.org.br/images/stories/biblioteca/codigo\%20de\%20etica\%20medica. pdf. Acesso em 11 maio 2019.

DOMINGUES, Felipe. Ministério diz que o termo 'violência obstétrica' é 'inadequado' e deixará de ser usado pelo governo. Portal G1. 07 maio 2019. Disponível em: https://g1.globo.com/ciencia-e-saude/noticia/2019/05/07/ministerio-diz-que-termoviolencia-obstetrica-tem-conotacao-inadequada-e-deixara-de-ser-usado-pelogoverno.ghtml. Acesso em: 07 maio 2019.

GUSTIN, Miracy Barbosa de Sousa; DIAS, Maria Tereza Fonseca. (Re)pensando a pesquisa jurídica: teoria e prática. 3ª . ed. Belo Horizonte: Del Rey, 2010.

LAZZERI, Thais. Vítimas da violência obstétrica: o lado invisível do parto. Portal Época. $\quad 04 \quad$ ago 2015.2 Disponível 
Personalidade Acadêmica Homenageada:

Raymundo Juliano Feitosa (Universidade Federal do Rio Grande do Norte - UFRN)

https://epoca.globo.com/vida/noticia/2015/08/vitimas-da-violencia-obstetrica-o-ladoinvisivel-do-parto.html. Acesso em: 12 maio 2019.

MEET our alumini. Portal University of California Berkeley. 25 jan 2010. Disponível

https://web.archive.org/web/20100610142323/http://ls.berkeley.edu/?q=alumni\%2Fm eet-our-alumni. Acesso em: 30 abr 2019.

MULHERES brasileiras e gênero no espaço público e privado. Portal Apublica. Ago $2010 . \quad$ Disponível em: https://apublica.org/wpcontent/uploads/2013/03/www.fpa_.org_.br_sites_default_files_pesquisaintegra.pdf. Acesso em: 11 maio 2019.

RUIZ, Ivan Aparecido; PINTO, Tatiana Coutinho Pita. Da violência psíquica contra a mulher e sua proteção insuficiente na ordem jurídica brasileira. Revista Jurídica Unicuritiba. V. $2, \quad$ n. 29 (2012). Disponível em: http://revista.unicuritiba.edu.br/index.php/RevJur/article/view/524/408. Acesso em 26 maio 2019.

SOLNIT, Rebecca. Os homens explicam tudo para mim. São Paulo: Cultrix, 2017.

TERZIAN, Peter. Room to Roam. Portal Columbia Journalism Review. Jul 2007. Disponível em: https://archives.cjr.org/q_and_a/room_to_roam.php. Acesso em: 30 abr 2019.

VIOLÊNCIA obstétrica. Portal Parto do Princípio. 20 out 2014. Disponível em: https://www.partodoprincipio.com.br/viol-ncia-obst-trica. Acesso em: 25 abr 2019

WITKER, Jorge. Como elaborar una tesis en derecho: pautas metodológicas y técnicas para el estudiante o investigador del derecho. Madrid: Civitas, 1985. 